\title{
Association between Food Intake, Clinical and Metabolic Markers and DNA Damage in Older Subjects
}

\author{
Cristian Del Bo' ${ }^{1} \mathbb{1}$, Daniela Martini ${ }^{1} \mathbb{1}$, Stefano Bernardi ${ }^{1}$, Letizia Gigliotti ${ }^{1}$, Mirko Marino ${ }^{1}$, \\ Giorgio Gargari ${ }^{1}$, Tomas Meroño ${ }^{2,3}{ }^{(}$, Nicole Hidalgo-Liberona 2,3 ${ }^{(0)}$, Cristina Andres-Lacueva ${ }^{2,3}$, Paul A. Kroon ${ }^{4}$, \\ Antonio Cherubini ${ }^{5}$, Simone Guglielmetti ${ }^{1}\left(\mathbb{D}\right.$, Marisa Porrini ${ }^{1, *}(\mathbb{C})$ and Patrizia Riso ${ }^{1, *(\mathbb{C})}$
}

1 Department of Food, Environmental and Nutritional Sciences (DeFENS), Università degli Studi di Milano, 20133 Milan, Italy; cristian.delbo@unimi.it (C.D.B.); daniela.martini@unimi.it (D.M.); stefanobernardi@mail.com (S.B.); letizia.gigliotti@unimi.it (L.G.); mirko.marino@unimi.it (M.M.); gargari.g@gmail.com (G.G.); simone.guglielmetti@unimi.it (S.G.)

2 Biomarkers and Nutrimetabolomics Laboratory, Department of Nutrition, Food Sciences and Gastronomy, XIA, INSA, CIBERFES-ISCIII, 08028 Barcelona, Spain; tomasmerono@ub.edu (T.M.); n.hidalgoliberona@ub.edu (N.H.-L.); candres@ub.edu (C.A.-L.)

3 Faculty of Pharmacy and Food Sciences, University of Barcelona, 08028 Barcelona, Spain

4 Quadram Institute Bioscience, Norwich Research Park, Norwich NR4 7UG, UK; paul.kroon@quadram.ac.uk

5 Geriatria, Accettazione Geriatrica e Centro di ricerca per l'invecchiamento, IRCCS INRCA, 60127 Ancona, Italy; a.cherubini@inrca.it

Citation: Del Bo', C.; Martini, D.; Bernardi, S.; Gigliotti, L.; Marino, M.; Gargari, G.; Meroño, T.;

Hidalgo-Liberona, N.;

Andres-Lacueva, C.; Kroon, P.A.; et al. Association between Food Intake, Clinical and Metabolic Markers and DNA Damage in Older Subjects. Antioxidants 2021, 10, 730. https:// doi.org/10.3390/antiox10050730

Academic Editors: Silvana Hrelia and Cristina Angeloni

Received: 2 April 2021

Accepted: 30 April 2021

Published: 6 May 2021

Publisher's Note: MDPI stays neutral with regard to jurisdictional claims in published maps and institutional affiliations.

Copyright: (c) 2021 by the authors. Licensee MDPI, Basel, Switzerland. This article is an open access article distributed under the terms and conditions of the Creative Commons Attribution (CC BY) license (https:/ / creativecommons.org/licenses/by/ $4.0 /)$.
* Correspondence: marisa.porrini@unimi.it (M.P.); patrizia.riso@unimi.it (P.R.); Tel.: +39-02-50316720 (M.P.); +39-02-50316726 (P.R.)

Abstract: The use of DNA damage as marker of oxidative stress, metabolic dysfunction and agerelated diseases is debated. The present study aimed at assessing the level of DNA damage (evaluated as DNA strand-breaks, endogenous and oxidatively-induced DNA damage) in a group of older subjects with intestinal permeability enrolled within the MaPLE (Gut and Blood Microbiomics for Studying the Effect of a Polyphenol-Rich Dietary Pattern on Intestinal Permeability in the Elderly) intervention trial, to evaluate its association with clinical, metabolic and dietary markers. DNA damage in peripheral blood mononuclear cells was assessed by the comet assay in 49 older subjects participating in the study. Clinical and metabolic markers, markers of inflammation, vascular function and intestinal permeability were determined in serum. Food intake was estimated by weighted food diaries. On the whole, a trend towards higher levels of DNA damage was observed in men compared to women $(p=0.071)$. A positive association between DNA damage and clinical/metabolic markers (e.g., uric acid, lipid profile) and an inverse association with dietary markers (e.g., vitamin C, E, $\mathrm{B}_{6}$, folates) were found and differed based on sex. By considering the importance of DNA stability during aging, the results obtained on sex differences and the potential role of dietary and metabolic factors on DNA damage underline the need for further investigations in a larger group of older adults to confirm the associations found and to promote preventive strategies.

Keywords: aging; DNA damage; diet; metabolic markers; older subjects

\section{Introduction}

DNA represents one of the most biologically significant targets of oxidative stress, and it is widely recognised that continuous oxidative damage to DNA may contribute to the development of numerous age-related diseases [1]. Different markers of oxidative DNA damage have been proposed and utilized in numerous studies present in literature [2]. One of the most widely used markers to assess DNA damage is represented by 8-hydroxy-2-deoxy-guanosine $(8-\mathrm{OHdG})[3,4]$. This marker can derive from oxidative damage and excision-repair, oxidation of free bases or nucleotides, but also from other nucleic acids. Free 8-OHdG can be determined in different biological samples such as blood, urine and tissues; however, urinary 8-OHdG does not directly reflect DNA oxidation 
within cells [5]. Another measurement of DNA damage can be performed through the use of comet assay [6,7]. The comet assay represents one of the most popular, versatile, simple, sensitive and non-invasive electrophoretic techniques able to detect, in individual cells, different types of damage (e.g., single and double-strand DNA breaks, alkali-labile lesions, DNA-DNA/DNA-protein cross-links) [8]. The comet assay is widely used in numerous in vitro and in vivo studies including observational and dietary intervention studies [9]. Measures of DNA damage using the traditional comet assay, which detect DNA strand breaks by the appearance of tailing, are not specific for oxidative damage. A direct measurement of oxidative damage to DNA (i.e., oxidised DNA bases) can be obtained in vivo by using modifications of the comet assay [10]. The most common modifications include the use of specific enzymes such as endonuclease III for the evaluation of oxidised pyrimidines, and formamidopyrimidine DNA glycosylase (FPG) for the detection and removal of the oxidatively damaged purines (e.g., 8-OHdG). This procedure allows a more direct measurement of DNA damage within the cells and a quantitative comparison with appropriate control $[10,11]$. A further comet protocol often utilised enables the evaluation of DNA susceptibility to oxidative damage generally induced by using $\mathrm{H}_{2} \mathrm{O}_{2}$. This assay can give further information on cell capacity to counteract an oxidative stress [9].

It has been suggested that there is an association between age and DNA damage [12]. Specifically, several factors can contribute in increasing the levels of DNA damage, from both intrinsic and extrinsic sources [13]. Aging is considered as a progressive and biological phenomenon that leads to loss of physiological integrity and to an impairment of numerous functions, at the molecular, cellular, tissue and organ level $[12,13]$. Several causes of aging have been hypothesized including an exacerbation of oxidative stress attributed to an imbalance between oxidant molecules and the antioxidant defence mechanisms [13]. This condition brings an accumulation of damage to macromolecules such as DNA but also carbohydrates, lipids, and proteins [14]. In this regard, one important aspect of the ageing process is the progressive accumulation of DNA damage over time [12]. A phenomenon strictly correlated with the aging process is inflammation. A greater presence of proinflammatory factors, such as interleukins (e.g., interleukin-6, IL-6; interleukin-1beta, IL-1 $\beta$ ) and cytokines (tumour necrosis factor alpha, TNF- $\alpha$ ) has been observed in older subjects contributing to generate a persistent and prolonged low-grade inflammation phenomenon called "inflamm-aging" [15]. Additionally, during inflammatory response, reactive oxygen and nitrogen species are produced to combat pathogens and to stimulate tissue repair and regeneration; however, these substances can also damage DNA and induce mutations.

Among the external factors that may contribute to the onset and progression of oxidative stress, and thus on DNA damage, diet and its components can play a pivotal role [16]. Several essential nutrients such as vitamins (e.g., folate, vitamin B12, niacin, vitamin C and E), minerals (e.g., magnesium, zinc, iron, manganese, selenium), and non-essential nutrients such as phytochemicals (e.g., polyphenols, carotenoids, and other bioactives) constitute a fundamental pillar for the preservation of DNA integrity due to their numerous important biological activities [17-23]. In fact, they are required for numerous functions including nucleotide synthesis, DNA replication, maintenance of DNA methylation, chromosome stability, prevention of DNA oxidation, DNA damage repair [24,25]. On the other hand, excessive energy intake, mainly from fats and in particular from saturated fatty acids, may bring to overweight/obesity and to increased levels of DNA damage also related to an alteration of the repair mechanisms [26]. This is quite common in older subjects in which physiological-social and environmental factors, oral-dental-deglutition disorders, dementia, long drug treatments can compromise the nutritional status thus potentially affecting DNA stability. In particular, several studies have reported that older subjects have higher levels of DNA damage compared to younger individuals $[27,28]$.

To date it is not possible to identify a predominant factor responsible for the levels of DNA damage in specific target groups, but it can be assumed that the damage may derive from a combination of multiple factors that directly or indirectly affect DNA stability. In this regard, it has been suggested that increased intestinal permeability (IP), promoting the 
translocation of inflammogenic factors could contribute to increase oxidative stress and inflammation, thus representing a further potential factor to control [29].

The main aim of the present study was to assess the levels of DNA damage in a group of older subjects with increased intestinal permeability enrolled in the MaPLE (Gut and Blood Microbiomics for Studying the Effect of a Polyphenol-Rich Dietary Pattern on Intestinal Permeability in the Elderly) study. The association of DNA damage with clinical, metabolic and dietary markers has been also investigated in order to identify the potential relationships in this target group.

\section{Materials and Methods}

\subsection{Setting and Subjects' Recruitment}

Fifty-one subjects completed the MaPLE trial carried out at Civitas Vitae (OIC Foundation, Padua, Italy), an institution including residential care and independent residences for older subjects [30]. Subjects were selected based on different inclusion and exclusion criteria as previously reported. Briefly, subjects had to be $\geq 60$ years old, with a good cognitive and nutritional status, and a general good health condition while presenting an increased IP evaluated as serum zonulin level [30]. Celiac disease, major renal, liver or respiratory dysfunctions were considered as exclusion criteria together with antibiotic treatment or malignant tumour in the near previous period. Volunteers recruited were non-smokers and information on past smoking habits was not collected. The MaPLE study protocol was approved by the Ethics Committee of the Università degli Studi di Milano (15 February 2016; ref.: 6/16/CE_15.02.16_Verbale_All-7) while the trial was registered in a public register (28 April 2017; ISRCTN10214981; http:/ / www.isrctn.com/ISRCTN10214981, accessed on 15 April 2021). Each participant received detailed information about the study purpose and procedures. Specifically, the MaPLE trial was aimed at demonstrating the role of a polyphenol-rich dietary pattern in the reduction of intestinal permeability and improvement of metabolic phenotypes in older adults. A written consent was obtained by each volunteer after acceptance. The full experimental design and inclusion and exclusion criteria were previously reported [30]. For the present study, the characteristics of subjects at baseline have been considered.

\subsection{Food Intake}

Food intake was collected through the analysis of weighed food diaries. In particular, subjects were asked to provide a food diary the day before the blood drawing. Data obtained were compared with those collected along the whole study in order to verify reproducibility of food habits of the volunteers. This was ensured thanks also to the moderate variety of the meals available within the standard menu provided at the nursing home [31]. The full protocol has been reported in a previous manuscript [30]. Energy, nutrient and polyphenol (single classes and total polyphenols assessed by Folin-Ciocalteu method) intake were estimated through the Metadieta software (Me.Te.Da S.r.l., Rome, Italy) and Phenol-explorer (phenol-explorer.eu).

\subsection{Anthropometric, Clinical and Metabolic Makers Analysis}

Weight, height, body mass index (BMI) and blood pressure were analysed according to international guidelines of Lohman et al. [32] and the Joint National Committee on Prevention, Detection, Evaluation, and Treatment of High Blood Pressure guidelines (JNC 7) [33], as previously described. Blood samples were collected after an overnight fasting for the analysis of a plethora of markers [30]. Plasma and serum were obtained as previously reported [30] and stored at $-80{ }^{\circ} \mathrm{C}$ until analysis. Metabolic markers (i.e., glycaemia, insulin, lipid profile, liver and renal function) were evaluated in serum through a validated protocol, using an automatic biochemical analyser (ILAB 650, Instrumentation Laboratory, Lexington, MA, USA). Inflammatory (e.g., IL-6, TNF- $\alpha$, C-reactive protein (CRP) and vascular function markers (i.e., vascular cell adhesion molecule 1, VCAM1; intercellular adhesion molecule 1, ICAM1) were analysed in serum through ELISA kits (R\&D System, 
Minneapolis, MN, USA). Finally, serum zonulin levels, as marker of IP, were quantified using the Immunodiagnostik ELISA kit (Bensheim, Germany) [34].

\subsection{Isolation of Peripheral Blood Mononuclear Cells}

Peripheral blood mononuclear cells (PBMCs) were separated by using Histopaque 1077 density gradient, according to the procedure reported by Del Bo' et al. [35]. Isolated PBMCs were then diluted into a medium constituted by fetal bovine serum, RPMI 1640 and dimethyl sulfoxide (50:40:10) and stored at $-80^{\circ} \mathrm{C}$ until analysis. The analysis of DNA damage was performed on PBMCs after a rapid thawing at $37^{\circ} \mathrm{C}$ followed by a washing step with fresh RPMI medium and cold phosphate buffer saline. For the analysis, both endogenous and oxidatively-induced DNA damage were evaluated by comet assay [35]. The analysis was performed on samples at baseline.

\subsection{Analysis of DNA Damage by the Comet Assay}

The evaluation of endogenous DNA damage as formamidopyrimidine DNA glycosylase (FPG) sensitive sites was carried out enzymatically by the use of FPG able to detect the oxidized purines (mainly 8-oxo-7,8-hydroxyguanine). A description of the specific steps and conditions of the protocol used has been previously reported [35]. In brief, a solution of low melting point agarose was added to PBMCs suspension, mixed and rapidly spotted onto GelBond Film (VWR International U.R.L., Monroeville, PA, USA) precoated with normal melting point agarose. Coverslips were added on top of the slides and left to solidify for a few minutes at $4{ }^{\circ} \mathrm{C}$. After solidification, coverslips were removed and slides were transferred into a lysis buffer for $1 \mathrm{~h}$ at $4{ }^{\circ} \mathrm{C}$ in the dark. Then, slides were washed 3 times in a cold buffer and further processed. One slide was treated with a buffer solution containing the FPG enzyme, while the other slide (control) with the same buffer without FPG. Samples were then incubated at $37^{\circ} \mathrm{C}$ for $45 \mathrm{~min}$. Successively, the slides were transferred in a horizontal electrophoresis tank containing an alkaline electrophoresis buffer for $40 \mathrm{~min}$ at $4{ }^{\circ} \mathrm{C}$ in order to favour DNA unwinding, followed by an electrophoresis step ( $25 \mathrm{~V}, 300 \mathrm{~mA}, 20 \mathrm{~min})$. Finally, samples were washed in a neutralizing buffer for $15 \mathrm{~min}$ at $4{ }^{\circ} \mathrm{C}$ in the dark and dried in ethanol for $2 \mathrm{~h}$.

Oxidatively induced DNA damage was assessed according to the procedure previously reported [35]. Briefly, two GelBonds Film containing cell suspensions were prepared for each subject: one was treated with hydrogen peroxide $\left(\mathrm{H}_{2} \mathrm{O}_{2} 500 \mu \mathrm{M}, 5 \mathrm{~min}\right)$ in a buffer solution at room temperature in the dark; the other was treated for 5 min only with the buffer solution (control slide). Following the oxidative treatment, slides were immersed in a lysis buffer for $1 \mathrm{~h}$ at $4{ }^{\circ} \mathrm{C}$ in the dark, and then transferred in a horizontal electrophoresis tank and treated as previously reported for the evaluation of endogenous DNA damage.

Ethidium bromide was used for the staining process. At least fifty comets per gel (i.e., 100 comets per condition) were scored using an epifluorescence microscope and analysed with an image analysis system (Cometa 1.5; Immagini e Computer, Bareggio, Milan, Italy). The levels of DNA damage were calculated as tail intensity (\% DNA in tail).

\subsection{Statistical Analysis}

Values were reported as mean \pm standard deviation (SD), median and interquartile range (IQR, $25-75^{\circ}$ percentile). Statistical analyses were performed by means of STATISTICA software (Statsoft Inc., Tulsa, OK, USA). Normality was assessed by the Shapiro-Wilk test. Significant differences at baseline based on sex were determined by unpaired Student's $t$ test. The regression and correlation analyses (Spearman and Kendall test) were carried out to highlight associations between the levels of DNA damage and dietary, clinical and metabolic parameters in the whole group of subjects and in women and men. In addition, volunteers were stratified according to clinical variables in quartiles, and significant differences in DNA damage biomarkers in each quartile were assessed by unpaired Student's $t$ test. Significance was set at $p \leq 0.05$; significance in the range $0.05<p<0.10$ was considered as a trend. 


\section{Results}

\subsection{Subject Characteristics}

Supplementary Table S1 reports the characteristics of 49 subjects ( 22 men, 27 women) enrolled within the MaPLE intervention study. The full data set has been already reported [34]. Briefly, subjects analysed ranged between 60 and 98 years old with a median value of 77 years. A high inter-individual variability was shown for BMI (IQR: 22.7-30.7), glucose levels (IQR: 87-113), total cholesterol (IQR: 167-237) (Table S1). Similar findings were observed for the levels of FPG-sensitive sites (IQR: 21.4-34.9) and $\mathrm{H}_{2} \mathrm{O}_{2}$-induced DNA damage (IQR: 9.0-24.0) also after stratification based on sex (Table 1). On the whole, data on DNA damage were comparable between groups. Only a trend towards higher, but not significant $(p=0.071)$, levels of FPG-sensitive sites was documented in men compared to women.

Table 1. Levels of DNA damage markers evaluated at baseline.

\begin{tabular}{ccccc}
\hline Marker of DNA Damage & $\begin{array}{c}\text { All } \\
(\boldsymbol{n}=\mathbf{4 9 )}\end{array}$ & $\begin{array}{c}\text { Men } \\
(\boldsymbol{n}=\mathbf{2 2})\end{array}$ & $\begin{array}{c}\text { Women } \\
(\boldsymbol{n}=\mathbf{2 7})\end{array}$ & $\boldsymbol{p}$-Value \\
\hline FPG-sensitive sites (\% DNA in tail) & $16.5 \pm 9.0$ & $18.6 \pm 10.4$ & $14.8 \pm 6.8$ & 0.071 \\
\hline $\begin{array}{c}\mathrm{H}_{2} \mathrm{O}_{2} \text {-induced DNA damage } \\
\text { (\% DNA in tail) }\end{array}$ & $28.7 \pm 11.4$ & $28.5 \pm 11.6$ & $29.0 \pm 2.4$ & 0.438 \\
\hline
\end{tabular}

Data are reported as mean \pm SD (standard deviation); $p<0.05$ are significantly different between groups. FPG formamidopyrimidine DNA glycosylase.

\subsection{Correlation between DNA Damage and Dietary Markers}

Supplementary Table S2 reports the data obtained for dietary markers in the 49 out of 51 subjects enrolled within the MaPLE intervention study. The full data set has been already reported [34]. In Table 2 are shown the correlations between the levels of DNA damage and the dietary markers (energy, macro and micronutrients, and polyphenols).

Regarding the levels of FPG-sensitive sites, an overall negative correlation was found in the whole group of subjects for the intake of vitamin $C(p=0.03)$, vitamin $\mathrm{E}(p=0.008)$, vitamin $\mathrm{B}_{6}(p=0.002)$ and folates $(p=0.008)$, while no significant correlations were evidenced for the rest of macro and micronutrients analysed. In addition, no association was also found when considering polyphenols and their subclasses.

As regards the levels of $\mathrm{H}_{2} \mathrm{O}_{2}$-induced DNA damage, an overall positive correlation was reported in the whole group of subjects with the intake of cholesterol $(p=0.003)$, omega 3 fatty acids $(p=0.021)$ and vitamin $\mathrm{B}_{6}(p=0.032)$, while no association emerged for the other dietary markers including polyphenols and the different subclasses analysed.

The analysis performed stratifying subjects based on sex (Table 3) did not show any significant correlation between the levels of DNA damage (both FPG-sensitive sites and $\mathrm{H}_{2} \mathrm{O}_{2}$-induced DNA damage) and the majority of the dietary markers. Regarding the levels of FPG-sensitive sites, a negative correlation was found with the intake of folates and vita$\min \mathrm{B}_{6}(p=0.004 ; p=0.046$, respectively) in women, and the intake of vitamin $\mathrm{E}(p=0.042)$ in men. In addition, a negative correlation with the intake of monounsaturated fatty acids (MUFA; $p=0.048$ ) was observed. No association was observed for polyphenols and their subclasses, apart from an apparent, but not significant $(p=0.052)$ inverse correlation found in men. Regarding the levels of $\mathrm{H}_{2} \mathrm{O}_{2}$-induced DNA damage, a positive correlation with dietary cholesterol $(p=0.010)$ and a negative correlation with total fibre intake $(p=0.049)$ was found in women, while in men no correlation was evidenced with the dietary markers considered including with the intake of polyphenols and their subclasses. 
Table 2. Correlation analysis between dietary markers and DNA damage in the whole group of subjects.

\begin{tabular}{|c|c|c|c|c|c|c|}
\hline \multirow{2}{*}{ Dietary Markers } & \multicolumn{3}{|c|}{ FPG-Sensitive Sites } & \multicolumn{3}{|c|}{$\mathrm{H}_{2} \mathrm{O}_{2}$-Induced Damage } \\
\hline & Tau & $Z$ & $p$-Level & Tau & $Z$ & $p$-Level \\
\hline Energy (kcal) & 0.064 & 0.650 & 0.516 & 0.023 & 0.234 & 0.815 \\
\hline Total Carbohydrates (\% of energy) & 0.021 & 0.217 & 0.828 & -0.032 & -0.322 & 0.748 \\
\hline Simple Carbohydrates (\% of energy) & -0.026 & -0.261 & 0.794 & -0.019 & -0.191 & 0.849 \\
\hline Proteins (\% of energy) & -0.016 & -0.167 & 0.867 & -0.032 & -0.325 & 0.745 \\
\hline Animal Proteins ( $\%$ of energy) & -0.067 & -0.675 & 0.500 & 0.051 & 0.517 & 0.605 \\
\hline Vegetal Proteins (\% of energy) & 0.013 & 0.135 & 0.893 & 0.038 & 0.386 & 0.700 \\
\hline Total Lipids (\% of energy) & -0.048 & -0.488 & 0.626 & 0.082 & 0.827 & 0.408 \\
\hline SFA (\% of energy) & -0.069 & -0.699 & 0.485 & 0.113 & 1.143 & 0.253 \\
\hline MUFA (\% of energy) & -0.137 & -1.387 & 0.165 & 0.099 & 1.000 & 0.317 \\
\hline PUFA (\%of energy) & -0.056 & -0.571 & 0.568 & 0.061 & 0.616 & 0.538 \\
\hline$\omega-6$ (\%of energy) & -0.112 & -1.131 & 0.258 & 0.082 & 0.835 & 0.404 \\
\hline$\omega-3$ (\%of energy) & -0.101 & -1.027 & 0.305 & 0.114 & 1.159 & 0.247 \\
\hline Total Fibre (g/1000 kcal) & -0.084 & -0.849 & 0.396 & -0.108 & -1.093 & 0.274 \\
\hline Cholesterol (mg) & 0.006 & 0.061 & 0.951 & 0.289 & 2.929 & 0.003 \\
\hline Calcium (mg) & -0.022 & -0.225 & 0.822 & 0.038 & 0.381 & 0.703 \\
\hline Iron (mg) & 0.157 & 1.596 & 0.110 & 0.016 & 0.158 & 0.875 \\
\hline Vitamin $B_{12}(\mathrm{mcg})$ & -0.002 & -0.019 & 0.985 & 0.161 & 1.632 & 0.103 \\
\hline Vitamin C (mg) & -0.294 & -2.978 & 0.003 & 0.123 & 1.245 & 0.213 \\
\hline Vitamin E (mg) & -0.262 & -2.653 & 0.008 & 0.083 & 0.843 & 0.399 \\
\hline Vitamin $B_{1}(\mathrm{mg})$ & -0.100 & -1.012 & 0.312 & 0.008 & 0.076 & 0.939 \\
\hline Folates (mcg) & -0.310 & -3.138 & 0.002 & 0.153 & 1.546 & 0.122 \\
\hline Vitamin $\mathrm{B}_{6}(\mathrm{mg})$ & -0.263 & -2.670 & 0.008 & 0.212 & 2.147 & 0.032 \\
\hline Flavonoids (mg) & 0.167 & 1.692 & 0.091 & 0.005 & 0.052 & 0.959 \\
\hline Lignans (mg) & -0.031 & -0.315 & 0.753 & 0.149 & 1.508 & 0.132 \\
\hline Other polyphenols (mg) & -0.135 & -1.370 & 0.171 & 0.124 & 1.255 & 0.210 \\
\hline Phenolic acids (mg) & -0.005 & -0.052 & 0.958 & 0.012 & 0.122 & 0.903 \\
\hline Stilbenes (mg) & 0.012 & 0.122 & 0.903 & -0.039 & -0.395 & 0.693 \\
\hline Total Polyphenols (mg) & 0.138 & 1.401 & 0.161 & -0.032 & -0.328 & 0.743 \\
\hline TPC Folin (mg) & -0.024 & -0.242 & 0.809 & -0.055 & -0.553 & 0.580 \\
\hline
\end{tabular}

Legend: Regression and correlation analyses obtained by Spearman and Kendall test. Data reported in bold are statistically significant $(p<0.05)$; FPG, formamidopyrimidine DNA glycosylase; SFA, saturated fatty acids; MUFA, monounsaturated fatty acids; PUFA, polyunsaturated fatty acids, $\omega-3$, omega- 3 fatty acids; $\omega-6$, omega- 6 fatty acids; TPC, total polyphenol content evaluated by Folin-Ciocalteu method.

\subsection{Correlation between the Levels of DNA Damage and Anthropometric, Metabolic and Clinical Markers}

In Table 4 the correlations between the levels of DNA damage and anthropometric, metabolic and clinical markers are reported. Despite not being significant $(p=0.086)$, an inverse association between the levels of FPG-sensitive sites and age was observed. On the whole, no correlation was found between FPG-sensitive sites and metabolic and clinical markers neither in the whole group of subjects nor following sex stratification (Table 5). 
Table 3. Correlation analysis between dietary markers and DNA damage in women and men.

\begin{tabular}{|c|c|c|c|c|c|c|c|c|c|c|c|c|}
\hline \multirow[b]{3}{*}{ Dietary Markers } & \multirow{2}{*}{\multicolumn{3}{|c|}{$\begin{array}{c}\text { Women } \\
\text { FPG-Sensitive Sites }\end{array}$}} & \multicolumn{9}{|c|}{ Men } \\
\hline & & & & \multicolumn{3}{|c|}{$\mathrm{H}_{2} \mathrm{O}_{2}$-Induced Damage } & \multicolumn{3}{|c|}{ FPG-Sensitive Sites } & \multicolumn{3}{|c|}{$\mathrm{H}_{2} \mathrm{O}_{2}$-Induced Damage } \\
\hline & Tau & $\mathbf{Z}$ & $p$-Level & Tau & $\mathbf{Z}$ & $p$-Level & Tau & $\mathrm{Z}$ & $p$-Level & Tau & $\mathbf{Z}$ & $p$-Level \\
\hline Energy (kcal) & 0.054 & 0.398 & 0.690 & -0.060 & -0.440 & 0.660 & 0.004 & 0.028 & 0.977 & 0.135 & 0.878 & 0.380 \\
\hline Total Carbohydrates (\% of energy) & -0.052 & -0.377 & 0.706 & 0.080 & 0.586 & 0.558 & 0.083 & 0.538 & 0.591 & -0.135 & -0.878 & 0.380 \\
\hline Simple Carbohydrates ( $\%$ of energy) & 0.040 & 0.293 & 0.769 & -0.034 & -0.251 & 0.802 & -0.113 & -0.735 & 0.462 & -0.035 & -0.226 & 0.821 \\
\hline Proteins ( $\%$ of energy) & -0.123 & -0.902 & 0.367 & -0.014 & -0.105 & 0.917 & 0.130 & 0.848 & 0.397 & -0.052 & -0.339 & 0.735 \\
\hline Animal Proteins ( $\%$ of energy) & -0.057 & -0.419 & 0.675 & -0.040 & -0.293 & 0.769 & 0.009 & 0.057 & 0.955 & 0.087 & 0.565 & 0.572 \\
\hline Vegetable Proteins ( $\%$ of energy) & -0.046 & -0.335 & 0.738 & -0.006 & -0.042 & 0.967 & 0.009 & 0.057 & 0.955 & 0.052 & 0.339 & 0.735 \\
\hline Total Lipids (\% of energy) & 0.100 & 0.734 & 0.463 & -0.054 & -0.398 & 0.690 & -0.191 & -1.243 & 0.214 & 0.234 & 1.526 & 0.127 \\
\hline SFA ( $\%$ of energy) & 0.109 & 0.796 & 0.426 & 0.046 & 0.335 & 0.738 & -0.182 & -1.187 & 0.235 & 0.139 & 0.904 & 0.366 \\
\hline PUFA (\%of energy) & 0.052 & 0.377 & 0.706 & 0.000 & 0.000 & 1.000 & -0.174 & -1.130 & 0.258 & 0.148 & 0.961 & 0.337 \\
\hline$\omega-6$ (\%of energy) & 0.052 & 0.379 & 0.705 & -0.017 & -0.126 & 0.899 & -0.253 & -1.646 & 0.100 & 0.148 & 0.965 & 0.335 \\
\hline$\omega-3$ (\%of energy) & -0.020 & -0.149 & 0.881 & 0.020 & 0.149 & 0.881 & -0.181 & -1.177 & 0.239 & 0.181 & 1.177 & 0.239 \\
\hline Total Fibre (g/1000 kcal) & -0.023 & -0.167 & 0.867 & -0.269 & -1.968 & 0.049 & -0.161 & -1.048 & 0.295 & 0.022 & 0.142 & 0.887 \\
\hline Cholesterol (mg) & 0.029 & 0.212 & 0.832 & 0.353 & 2.584 & 0.010 & -0.052 & -0.341 & 0.733 & 0.200 & 1.306 & 0.192 \\
\hline Calcium (mg) & 0.063 & 0.461 & 0.645 & -0.137 & -1.005 & 0.315 & -0.087 & -0.565 & 0.572 & 0.148 & 0.961 & 0.337 \\
\hline Iron (mg) & 0.114 & 0.837 & 0.402 & -0.097 & -0.712 & 0.477 & 0.200 & 1.300 & 0.194 & 0.052 & 0.339 & 0.735 \\
\hline Vitamin $B_{12}(\mathrm{mcg})$ & -0.036 & -0.264 & 0.791 & 0.181 & 1.322 & 0.186 & 0.113 & 0.738 & 0.461 & 0.131 & 0.856 & 0.392 \\
\hline Vitamin C (mg) & -0.263 & -1.926 & 0.054 & 0.057 & 0.419 & 0.675 & -0.300 & -1.954 & 0.051 & 0.170 & 1.105 & 0.269 \\
\hline Vitamin E (mg) & -0.172 & -1.260 & 0.208 & -0.046 & -0.336 & 0.737 & -0.312 & -2.035 & 0.042 & 0.200 & 1.300 & 0.194 \\
\hline Vitamin $B_{1}(\mathrm{mg})$ & -0.035 & -0.253 & 0.801 & -0.109 & -0.800 & 0.424 & -0.083 & -0.540 & 0.589 & 0.031 & 0.199 & 0.842 \\
\hline Folates (mcg) & -0.391 & -2.864 & 0.004 & 0.197 & 1.443 & 0.149 & -0.229 & -1.494 & 0.135 & 0.100 & 0.649 & 0.517 \\
\hline Vitamin B 6 (mg) & -0.273 & -1.998 & 0.046 & 0.043 & 0.315 & 0.752 & -0.244 & -1.589 & 0.112 & 0.288 & 1.873 & 0.061 \\
\hline Lignans (mg) & 0.009 & 0.064 & 0.949 & 0.155 & 1.138 & 0.255 & -0.115 & -0.751 & 0.453 & 0.177 & 1.156 & 0.248 \\
\hline Phenolic acids (mg) & -0.011 & -0.084 & 0.933 & 0.114 & 0.835 & 0.404 & -0.056 & -0.367 & 0.714 & -0.091 & -0.592 & 0.554 \\
\hline Stilbenes (mg) & -0.060 & -0.442 & 0.659 & 0.226 & 1.657 & 0.098 & -0.233 & -1.519 & 0.129 & 0.069 & 0.447 & 0.655 \\
\hline Other polyphenols (mg) & 0.006 & 0.042 & 0.967 & 0.074 & 0.544 & 0.586 & -0.299 & -1.946 & 0.052 & 0.152 & 0.987 & 0.324 \\
\hline Total_Polyphenols (mg) & 0.060 & 0.438 & 0.662 & 0.048 & 0.354 & 0.723 & 0.143 & 0.931 & 0.352 & -0.100 & -0.649 & 0.517 \\
\hline TPC_Folin (mg) & 0.157 & 1.147 & 0.252 & -0.003 & -0.021 & 0.983 & -0.195 & -1.269 & 0.204 & -0.126 & -0.818 & 0.414 \\
\hline
\end{tabular}

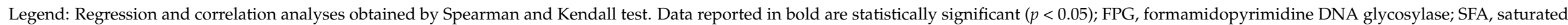
fatty acids; MUFA, monounsaturated fatty acids; PUFA, polyunsaturated fatty acids, $\omega-3$, omega-3 fatty acids; $\omega-6$, omega- 6 fatty acids; TPC, total polyphenol content. 
Table 4. Correlation analysis between anthropometric, metabolic and clinical markers and DNA damage in the whole group of subjects.

\begin{tabular}{ccccccc}
\hline \multirow{2}{*}{ Metabolic and } & \multicolumn{3}{c}{ FPG-Sensitive Sites } & \multicolumn{2}{c}{$\mathbf{H}_{\mathbf{2}} \mathbf{O}_{\mathbf{2}}$-Induced Damage } \\
\cline { 2 - 6 } Clinical Markers & Tau & $\mathbf{Z}$ & $\boldsymbol{p}$-Level & Tau & $\boldsymbol{Z}$ & $\boldsymbol{p}$-Level \\
\hline Age (y) & -0.169 & -1.715 & 0.086 & 0.119 & 1.210 & 0.226 \\
Weight (kg) & 0.104 & 1.053 & 0.292 & -0.210 & -2.124 & $\mathbf{0 . 0 3 4}$ \\
BMI (kg/m ${ }^{2}$ ) & 0.063 & 0.638 & 0.524 & -0.201 & -2.034 & $\mathbf{0 . 0 4 2}$ \\
SBP (mm Hg) & 0.011 & 0.107 & 0.915 & -0.163 & -1.653 & 0.098 \\
DBP (mm Hg) & 0.142 & 1.435 & 0.151 & -0.225 & -2.283 & $\mathbf{0 . 0 2 2}$ \\
Glucose (mg/dL) & 0.039 & 0.399 & 0.690 & -0.060 & -0.608 & 0.543 \\
Creatinine (mg/dL) & 0.009 & 0.086 & 0.931 & -0.044 & -0.450 & 0.653 \\
Uric Acid (mg/dL) & 0.013 & 0.131 & 0.896 & 0.083 & 0.844 & 0.398 \\
TC (mg/dL) & -0.130 & -1.314 & 0.189 & 0.087 & 0.881 & 0.378 \\
HDL-C (mg/dL) & -0.048 & -0.487 & 0.626 & -0.045 & -0.452 & 0.651 \\
TC/HDL (ratio) & -0.083 & -0.845 & 0.398 & 0.133 & 1.345 & 0.179 \\
LDL-C (mg/dL) & -0.123 & -1.245 & 0.213 & 0.135 & 1.367 & 0.172 \\
LDL/HDL (ratio) & -0.128 & -1.302 & 0.193 & 0.166 & 1.682 & 0.093 \\
TG (mg/dL) & -0.001 & -0.009 & 0.993 & 0.037 & 0.372 & 0.710 \\
AST (U/L) & 0.029 & 0.292 & 0.770 & -0.212 & -2.151 & $\mathbf{0 . 0 3 1}$ \\
ALT (U/L) & 0.111 & 1.122 & 0.262 & -0.252 & -2.554 & $\mathbf{0 . 0 1 1}$ \\
GGT (U/L) & 0.113 & 1.149 & 0.251 & -0.137 & -1.392 & 0.164 \\
Insulin (uU/mL) & -0.043 & -0.432 & 0.665 & -0.128 & -1.297 & 0.194 \\
HOMA Index & 0.009 & 0.086 & 0.931 & -0.119 & -1.207 & 0.228 \\
C-G index & 0.119 & 1.207 & 0.228 & -0.087 & -0.879 & 0.379 \\
Zonulin (ng/mL) & 0.017 & 0.172 & 0.863 & -0.063 & -0.638 & 0.524 \\
sCAM-1 (ng/mL) & 0.027 & 0.276 & 0.783 & 0.022 & 0.224 & 0.823 \\
sVCAM-1 (ng/mL) & -0.097 & -0.983 & 0.326 & 0.133 & 1.345 & 0.179 \\
CRP (mg/L) & 0.085 & 0.862 & 0.389 & 0.172 & 1.741 & 0.082 \\
TNF- $\alpha(\mathrm{pg} / \mathrm{mL})$ & -0.107 & -1.086 & 0.277 & 0.065 & 0.655 & 0.512 \\
IL-6 (pg/mL) & -0.050 & -0.509 & 0.611 & 0.076 & 0.767 & 0.443 \\
\hline
\end{tabular}

Legend: Regression and correlation analyses obtained by Spearman and Kendall test. Data reported in bold are statistically significant $(p<0.05)$; BMI, body mass index; SBP, systolic blood pressure; DBP, diastolic blood pressure; TC, Total cholesterol, HDL-C, high density lipoprotein-cholesterol; LDL-C, low density lipoprotein-cholesterol; TG, triglycerides; AST, aspartate aminotransferase; ALT, alanine aminotransferase; GGT, gamma-glutamyl transpeptidase; HOMA index, homeostasis model assessment index; C-G index, Cockcroft-Gault index; sVCAM1, vascular cells adhesion molecules-1; ICAM-1, intercellular adhesion molecules-1; CRP, C-reactive protein; TNF- $\alpha$, tumour necrosis factor alpha; IL-6, interleukin-6.

As regards the levels of $\mathrm{H}_{2} \mathrm{O}_{2}$-induced DNA damage (Table 4), a negative correlation was found with weight $(p=0.034)$, BMI $(p=0.042)$, diastolic blood pressure (DBP: $p=0.022)$, aspartate transaminase (AST: $p=0.031$ ) and alanine transaminase (ALT: $p=0.011$ ). Interestingly, the distribution of data in quartiles showed a lower level of DNA damage in subjects with the highest BMI, compared to those with the lowest BMI. Conversely, the subjects with the highest low density lipoprotein/high density lipoprotein ratio (LDL/HDL ratio) showed the highest DNA damage (Supplementary Figure S1). Stratification on the basis of HOMA index and CRP showed only a trend towards an increase of $\mathrm{H}_{2} \mathrm{O}_{2}$-induced DNA damage between the first and fourth quartile. No correlation was found for any of the other markers analysed.

After sex stratification (Table 5), a positive correlation between the levels of $\mathrm{H}_{2} \mathrm{O}_{2}$ induced DNA damage and both uric acid $(p=0.042)$ and LDL/HDL ratio $(p=0.035)$ were found for women, while a negative correlation was observed with BMI $(p=0.032)$. Regarding men, statistical analysis revealed a negative correlation between the levels of $\mathrm{H}_{2} \mathrm{O}_{2}$-induced DNA damage and DBP $(p=0.039)$ and ALT $(p=0.035)$. No correlation was shown for the rest of the markers under study both in men and women. 
Table 5. Correlation analysis between anthropometric, metabolic and clinical markers and DNA damage in women and men.

\begin{tabular}{|c|c|c|c|c|c|c|c|c|c|c|c|c|}
\hline \multirow{3}{*}{ Markers } & \multirow{2}{*}{\multicolumn{3}{|c|}{$\begin{array}{c}\text { Women } \\
\text { FPG-Sensitive Sites }\end{array}$}} & \multicolumn{9}{|c|}{ Men } \\
\hline & & & & \multicolumn{3}{|c|}{$\mathrm{H}_{2} \mathrm{O}_{2}$-Induced Damage } & \multicolumn{3}{|c|}{ FPG-Sensitive Sites } & \multicolumn{3}{|c|}{$\mathrm{H}_{2} \mathrm{O}_{2}$-Induced Damage } \\
\hline & Tau & $Z$ & $p$-Level & Tau & $Z$ & $p$-Level & Tau & $Z$ & $p$-Level & Tau & $Z$ & $p$-Level \\
\hline Weight (kg) & 0.114 & 0.835 & 0.404 & -0.171 & -1.253 & 0.210 & 0.057 & 0.368 & 0.713 & -0.143 & -0.935 & 0.350 \\
\hline $\mathrm{BMI}(\mathrm{kg} / \mathrm{m} 2)$ & 0.048 & 0.354 & 0.723 & -0.293 & -2.147 & 0.032 & 0.108 & 0.705 & 0.481 & -0.117 & -0.761 & 0.446 \\
\hline $\mathrm{SBP}(\mathrm{mm} \mathrm{Hg})$ & -0.178 & -1.302 & 0.193 & -0.136 & -0.998 & 0.318 & 0.149 & 0.974 & 0.330 & -0.202 & -1.317 & 0.188 \\
\hline $\mathrm{DBP}(\mathrm{mm} \mathrm{Hg})$ & 0.081 & 0.590 & 0.555 & -0.158 & -1.159 & 0.246 & 0.156 & 1.018 & 0.309 & -0.317 & -2.066 & 0.039 \\
\hline Creatinine (mg/dL) & -0.080 & -0.586 & 0.558 & -0.029 & -0.209 & 0.834 & -0.066 & -0.427 & 0.670 & -0.118 & -0.768 & 0.442 \\
\hline Uric Acid (mg/dL) & -0.020 & -0.147 & 0.883 & 0.278 & 2.034 & 0.042 & 0.031 & 0.199 & 0.842 & -0.100 & -0.654 & 0.513 \\
\hline $\mathrm{TC}(\mathrm{mg} / \mathrm{dL})$ & -0.120 & -0.877 & 0.381 & 0.000 & 0.000 & 1.000 & -0.121 & -0.791 & 0.429 & 0.130 & 0.848 & 0.397 \\
\hline HDL-C (mg/dL) & 0.000 & 0.000 & 1.000 & -0.184 & -1.348 & 0.178 & -0.061 & -0.399 & 0.690 & 0.079 & 0.513 & 0.608 \\
\hline TC/HDL (ratio) & -0.094 & -0.688 & 0.491 & 0.236 & 1.730 & 0.084 & -0.082 & -0.536 & 0.592 & 0.108 & 0.705 & 0.481 \\
\hline LDL-C (mg/dL) & -0.160 & -1.169 & 0.242 & 0.114 & 0.835 & 0.404 & -0.061 & -0.396 & 0.692 & 0.121 & 0.791 & 0.429 \\
\hline LDL/HDL (ratio) & -0.134 & -0.980 & 0.327 & 0.288 & 2.106 & 0.035 & -0.134 & -0.874 & 0.382 & 0.126 & 0.818 & 0.414 \\
\hline $\mathrm{TG}(\mathrm{mg} / \mathrm{dL})$ & 0.003 & 0.021 & 0.983 & 0.060 & 0.440 & 0.660 & -0.004 & -0.028 & 0.977 & 0.004 & 0.028 & 0.977 \\
\hline AST (U/L) & 0.070 & 0.514 & 0.607 & -0.170 & -1.243 & 0.214 & -0.089 & -0.581 & 0.562 & -0.223 & -1.451 & 0.147 \\
\hline GGT (U/L) & 0.124 & 0.909 & 0.363 & 0.043 & 0.317 & 0.751 & 0.035 & 0.227 & 0.820 & -0.244 & -1.589 & 0.112 \\
\hline Insulin $(\mathrm{uU} / \mathrm{mL})$ & 0.009 & 0.063 & 0.950 & -0.117 & -0.855 & 0.393 & -0.083 & -0.538 & 0.591 & -0.152 & -0.991 & 0.322 \\
\hline HOMA Index & 0.060 & 0.438 & 0.662 & -0.054 & -0.396 & 0.692 & -0.013 & -0.085 & 0.933 & -0.169 & -1.100 & 0.271 \\
\hline C-G index & 0.094 & 0.688 & 0.491 & -0.123 & -0.896 & 0.370 & 0.091 & 0.592 & 0.554 & -0.030 & -0.197 & 0.844 \\
\hline Zonulin (ng/mL) & -0.020 & -0.146 & 0.884 & -0.088 & -0.646 & 0.518 & 0.048 & 0.310 & 0.756 & -0.022 & -0.141 & 0.888 \\
\hline sICAM-1 (ng/mL) & 0.048 & 0.354 & 0.723 & 0.151 & 1.105 & 0.269 & -0.013 & -0.085 & 0.933 & -0.100 & -0.649 & 0.517 \\
\hline sVCAM-1 (ng/mL) & -0.037 & -0.271 & 0.786 & 0.077 & 0.563 & 0.574 & -0.108 & -0.705 & 0.481 & 0.255 & 1.664 & 0.096 \\
\hline $\mathrm{CRP}(\mathrm{mg} / \mathrm{L})$ & 0.014 & 0.104 & 0.917 & 0.174 & 1.272 & 0.203 & 0.160 & 1.043 & 0.297 & 0.229 & 1.494 & 0.135 \\
\hline TNF- $\alpha(\mathrm{pg} / \mathrm{mL})$ & -0.014 & -0.104 & 0.917 & 0.111 & 0.813 & 0.416 & -0.212 & -1.382 & 0.167 & -0.022 & -0.141 & 0.888 \\
\hline IL-6 (pg/mL) & -0.066 & -0.479 & 0.632 & 0.105 & 0.771 & 0.441 & 0.056 & 0.367 & 0.714 & 0.039 & 0.254 & 0.800 \\
\hline
\end{tabular}

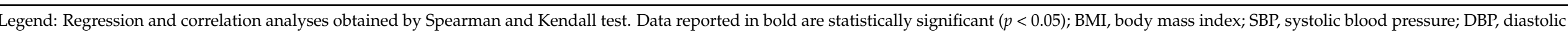

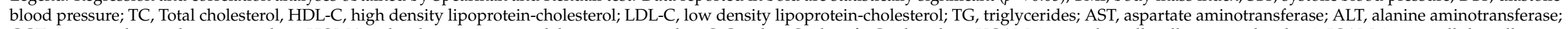

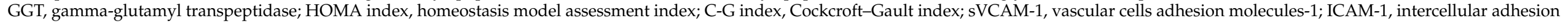
molecules-1; CRP, C-reactive protein; TNF- $\alpha$, tumour necrosis factor alpha; IL-6, interleukin-6; FPG, formamidopyrimidine DNA glycosylase. 


\section{Discussion}

The aging process can be considered a significant determinant of DNA damage levels due to increased oxidative stress, inflammation and other age-related conditions. However, available studies do not always report univocal results, in particular when DNA damage is evaluated by using the comet assay [9,36-38].

In the present study, we could not demonstrate a significant correlation between age or sex on DNA damage. However, it was observed a trend towards an inverse association between the levels of FPG-sensitive sites (endogenous DNA damage) and age, and a higher (but still not significant) level of damage in men compared to women, we may attribute to the limited sample size analysed.

As regards the discrepancy among the results found in literature on the topic, it could be related to many potential confounding factors. In this regard, the findings of a recent review showed that lifestyle factors, including diet, and other external exposures may contribute to the damage during aging more than age and sex itself [39].

Diet and dietary components have been largely studied for their modulatory effects on numerous biological functions including the protection against oxidative stress. These factors can contribute to the positive/negative modulation of DNA damage during the aging process. In our study, one of the main results observed regards the inverse association between dietary fibre and vitamins and the levels of DNA damage, and the positive association found with dietary lipids and cholesterol. A plethora of research has reported a positive and/or inverse association between DNA damage and specific dietary patterns $[40,41]$ and/or different macro/micronutrients intake $[9,16]$. For example, the amount of dietary fats and calories has been reported to play a role in the modulation of oxidative DNA damage levels. In fact, high dietary fat consumption contributes to free radical-induced lipid peroxidation causing damage to macromolecules, including enzymes and DNA [16]. In particular, the intake of saturated fatty acids (SFAs) appeared to be an important determinant of basal DNA damage, on the contrary monounsaturated fatty acids (MUFAs) and polyunsaturated fatty acids (PUFAs), specifically omega-3, have been associated with a reduced level of damage [16,42].

In our experimental conditions, the subjects enrolled had an overall good nutritional status [34]; in addition, there were no significant differences between women and men for any of the dietary variables evaluated [31]. This is in part due to the homogenous food choices related to the availability of meals provided through the daily menu at the nursing home. However, we found a positive association between the intake of dietary cholesterol and the levels of oxidatively induced-DNA damage. This positive association was also confirmed when considering differences according to sex, in particular a positive association with total cholesterol was observed in women while an inverse association with MUFA in men.

As regards dietary fibre, it plays a key role in human health and its intake is associated with a reduction in weight gain, the incidence of diabetes, obesity prevalence, hypercholesterolemia, inflammation and indirectly also reduced oxidative stress [43,44]. Overall, the intake of fibre in our population was relatively low (i.e., about 17-18 g/day) [31] with respect to dietary recommendation (at least $25 \mathrm{~g}$ /day) defined by Italian and international guidelines. Statistical analysis did not show any inverse association between total fibre intake (adjusted for energy intake) and the levels of DNA damage. However, when considering data stratified by sex, an inverse association was found in women.

Also vitamins and minerals can contribute in the modulation of activities against DNA damage [25]. For example, the intake of vitamin $C$ and vitamin $E$ has been found inversely associated with the levels of 8-oxodG and DNA strand breaks [45]. Similarly, folates, vitamin $\mathrm{B}_{6}$ and $\mathrm{B}_{12}$ have been associated with lower risk of single and double DNA strand breaks [45-48]. Among minerals, magnesium, calcium, iron, copper, zinc and selenium have been found inversely associated with DNA damage $[49,50]$ probably due to their role in the functioning of numerous antioxidant enzymes [25]. However, other studies have found a positive correlation between high calcium and iron intake and DNA 
damage [51,52]. In our trial, we did not underline critical vitamin and mineral intakes [31]. However, interestingly, we have found an inverse association between the levels of FPGsensitive sites and the intake of vitamin $C$, vitamin $E$, folates and vitamin $B_{6}$, while no correlations were found with the intake of minerals. The inverse associations were also confirmed when stratifying subjects by sex further underlying the importance of adequate vitamin intake in this target population.

Besides macro and micronutrients, also the protective effect of bioactives such as polyphenols against oxidative stress has been largely investigated [18]. A number of studies have shown the capacity of these compounds to neutralize the harmful effect of reactive oxygen species as well as to disrupt their propagation [53,54]. Furthermore, several studies have reported their ability to increase the activity of numerous antioxidant enzymes (e.g., catalase, superoxide dismutase, glutathione peroxidase) and to upregulate nuclear factor erythroid-related factor and antioxidant-responsive elements, crucial for the modulation of oxidative stress and thus DNA damage [53,54]. In this regard, a recent review has documented the capacity of polyphenols to protect cells from DNA damage suggesting it could be dependent on the type and amount of polyphenols tested, especially in in vitro studies where the doses administered can be very high with respect to an in vivo situation [48]. In fact, several in vitro studies reported an apparent increase in the levels of DNA damage after supraphysiological concentrations of polyphenols.

The contribution of polyphenols in the modulation of DNA damage has been documented also in numerous human trials $[55,56]$ showing a decrease in endogenous and oxidatively induced-DNA damage after administration of dietary doses of polyphenols and/or polyphenol-rich foods in different target group of population [57-60].

In the present study, we estimated a total dietary polyphenol intake of about $660 \mathrm{mg} /$ day (data based on Folin-Ciocalteau analysis as reported in the Phenol-Explorer database and other literature) as previously reported [31], with flavonoids and phenolic acids as the most consumed polyphenol classes. The intake was comparable between women and men and in line with other studies performed in the Italian population (In Chianti study) [61], but apparently lower if compared to the intake of other target populations [57]. Moreover, we could not find any significant association between total polyphenols or subclasses intake, and the levels of DNA damage, apart from an apparent, but not significant, inverse correlation in men. It is also noteworthy that we could not demonstrate in our group of older subjects the protective effect of these bioactive compounds against DNA damage even following a polyphenol rich dietary pattern [34].

In our study, we also tried to identify the possible relationship between anthropometric, clinical and metabolic markers, and the levels of DNA damage. It is widely recognized that metabolic and clinical markers such as glycaemia, insulin, lipid profile, blood pressure together with inflammatory markers (e.g., CRP, IL-6, TNF- $\alpha$ ), as well as body weight and BMI, may represent important determinants in the onset and/or progression of oxidative stress [9]. As previously reported, these variables were in the normal range in our target group apart from an overall mild overweight (mean BMI $27 \mathrm{~kg} / \mathrm{m}^{2}$ ) [34].

We did not evidence associations between endogenous DNA damage, as FPG-sensitive sites, and the markers under evaluation, even if an apparent trend for age $(p=0.086)$ was underlined. On the contrary we have found an unexplained inverse association between the levels of $\mathrm{H}_{2} \mathrm{O}_{2}$-induced DNA damage (as marker of cell resistance to oxidative stress) and BMI, body weight and DBP while only a trend towards a positive association with SBP, LDL/HDL ratio and CRP. After sex stratification, the associations seemed to be sexspecific (e.g., the inverse correlation with renal/liver function enzymes, DBP, body weight and BMI). Despite some cross-sectional studies that have reported results in line with our findings, a large number of human trials documented a positive association between overweight/obesity and DNA strand breaks or oxidative DNA damage [45,62,63]. A possible explanation for these conflicting results could be related to the cryopreservation process that could have activated a further metabolic activity in the frozen cells that make them more resistant when exposed to an oxidative stress condition, as already reported [35]. 
In addition, we may hypothesize that the inverse association found between the levels of $\mathrm{H}_{2} \mathrm{O}_{2}$-induced DNA damage and body weight and BMI could be related to catalase activity. This enzyme is involved in the conversion of $\mathrm{H}_{2} \mathrm{O}_{2}$ to hydrogen and water. Some studies have reported higher catalase activity in overweight/obese subjects compared to lean individuals as a compensatory mechanism to counterbalance an oxidative stress condition and an increase in the metabolic production of $\mathrm{H}_{2} \mathrm{O}_{2}$ in these subjects $[64,65]$. Although this could partially explain the inverse correlation found between DNA damage and BMI, the lack of data on enzymatic activity and the mild overweight of the subjects makes this consideration only a speculation.

Regarding the other metabolic markers under study, a positive association was depicted with LDL/HDL ratio (significant) and total cholesterol/HDL ratio (not significant) in women, supporting the contribution of dietary and circulating lipids in the increase of DNA damage as also reported in literature in different target groups [42,66,67]. Another interesting positive correlation was observed between the levels of uric acid and DNA damage evaluated following the ex vivo induced oxidative stress. Uric acid is the major endogenous end-product of purine metabolism. Experimental and clinical evidence suggests that uric acid could play an important role as antioxidant and could be involved in DNA repair mechanisms [68,69]. However, at the same time, high levels of uric acid were recognized as a marker of acute, severe and chronic inflammatory states [70,71]. In addition, evidence exists, mainly based on epidemiological studies, that high uric acid levels can be considered as an important risk factor for oxidative stress and may contribute to an early onset of cardiovascular, renal and metabolic diseases [72]. It is worth noting that in our population the levels of this marker were within the normal range, thus these findings should be further investigated to support the significance of the association in the older subjects also in view of recent published results [73].

Finally, in the present investigation we could not evidence any relationship between serum zonulin levels, evaluated as a marker of IP, and the different DNA damage markers analysed. The selection of subjects based on their increased IP and small sample size could justify the lack of significant relationships. This result cannot be considered conclusive since no other data have been previously published, although it may be considered plausible that an increased IP, often linked to age related dysbiosis, could promote higher oxidative stress $[74,75]$.

The results obtained in the present study are preliminary and the overall approach has some strengths related to the type of population under study and the specific setting enabling the control of numerous variables, including diet. However, some limitations are worth to be highlighted. First of all, the number of subjects enrolled does not allow a definitive conclusion above all by considering the high inter-individual variability in DNA damage levels found in our study and reported also in the literature. In addition, the lack of an actual analysis of nutritional status through adequate biomarker of intake could represent a further limitation.

\section{Conclusions}

In conclusion, the results obtained support the association among some dietary and clinical/metabolic markers and the levels of DNA damage in older subjects. However, further investigations are needed to confirm the association found in a larger group of older individuals in which also the impact of other confounding factors should be considered.

Supplementary Materials: The following are available online at https:/ / www.mdpi.com/article/10 .3390 /antiox10050730/s1, Figure S1: Levels of $\mathrm{H}_{2} \mathrm{O}_{2}$-induced DNA damage stratified by quartiles of body mass index (A), LDL/HDL ratio (B), triglycerides (C), HOMA-index (D) and C-reactive protein (E). Table S1: Baseline characteristics of subjects selected for the study, Table S2: Nutrient and polyphenol intake at baseline.

Author Contributions: P.R. and S.G. are responsible for the trial conception and design, and funding acquisition, and in collaboration with A.C., C.A.-L. and P.A.K. contributed to the development of 
study protocol for clinical and ethical aspects and to the selection of biochemical markers under study from a clinical perspective. C.D.B., D.M. and S.B. drafted the manuscript; C.D.B. and S.B. collected the samples and performed the analysis of clinical and metabolic markers; S.B., L.G., M.M. performed the analysis of comet assay under C.D.B., P.R., and M.P. supervision and contributed to the draft of the manuscript; T.M., N.H.-L. performed the analysis on polyphenol intake; L.G. and G.G. performed the statistical analysis. Finally, P.R., S.G., M.P., T.M.; N.H.-L., C.A.-L., P.A.K., critically reviewed and edited the manuscript. All authors have read and agreed to the published version of the manuscript.

Funding: This work was completed as part of the MAPLE project (Gut and Blood Microbiomics for Studying the Effect of a Polyphenol-Rich Dietary Pattern on Intestinal Permeability in the Elderly) supported within the European Joint Programming Initiative "A Healthy Diet for a Healthy Life" (JPI HDHL, http: / / www.healthydietforhealthylife.eu/, accessed on 10 April 2021) granted by Mipaaf (Italy, D.M. 8245/7303/2016), MINECO (Spain, PCIN-2015-238), and BBSRC (U.K., BB/R012512/1). Cristina Andres-Lacueva was also supported by ERA-Net cofound on Intestinal Microbiomics (ERA HDHL INTIMIC JPI HDHL) Project AC19/00096, and CIBERFES funded by Instituto de Salud Carlos III and co-funded by European Regional Development Fund "A way to make Europe", grant 2017SGR1546 from the Generalitat de Catalunya's Agency AGAUR, and ICREA Academia Award 2018. Additional funding was provided by the Biotechnology and Biological Sciences Research Council (UK) through an Institute Strategic Programme Grant ('Food Innovation and Health'; Grant No. BB/R012512/11 and its constituent projects BBS/E/F/000PR10343 (Theme 1, Food Innovation) and BBS/E/F/000PR10346 (Theme 3, Digestion and Fermentation in the Lower GI Tract) to the Quadram Institute Bioscience. Cristian Del Bo' was supported by "Piano di sostegno alla ricercaLinea 2, Azione A, Università degli Studi di Milano, DeFENS-grant number PSR2020-CDELB". TM would like to thank the "Juan de la Cierva" program from MINECO (IJCI-2017-32534). Patrizia Riso: Cristian Del Bo', Simone Guglielmetti and Giorgio Gargari acknowledge also the HDHL-INTIMIC Knowledge Platform on Food, Diet, Intestinal Microbiomics and Human Health (JPI-HDHL) with national funding by MIPAAF (D.M. 36959/7303/18-27 December 2018) to: “TOwards Personalised NUTRition concept through GUT microbiota modulation (TOPNUTRIGUT)". Cristian Del Bo' and Patrizia Riso acknowledge the European Cooperation for Science and Technology (COST Action) CA16112 "NutRedOx: Personalized Nutrition in Aging Society: Redox Control of Major Age-related Diseases" and the European Cooperation in Science and Technology (CA COST Action CA15132-The comet assay as a human biomonitoring tool (hCOMET)).

Institutional Review Board Statement: The study was conducted according to the guidelines of the Declaration of Helsinki and approved by the Ethics Committee) of the University of Milan (15 February 2016, ref: 6/16 CE_15.02.16_Verbale_All-7). The trial was prospectively registered (28 April 2017; ISRCTN10214981).

Informed Consent Statement: Informed consent was obtained from all subjects involved in the study.

Data Availability Statement: The data presented in this study are available on request from the corresponding author.

Acknowledgments: Authors would like to sincerely thank all the volunteers for their valuable contribution and dedication to the study. We are grateful to the nursing and medical staff working at Opera Immacolata Concezione (OIC Foundation, Padua, Italy) for their coordinating activities in the nursing home and for the success of the study. In particular, we would like to acknowledge Alberto Fantuzzo, Chiara Cavazzini, Lorella Pinton, Paolo Bergantin, Rosanna Ceccato, Pamela Soranzo, and Silvana Giraldini. We are also grateful to all the physicians (Michela Rigon, Lorena D'Aloise, Antonio Merlo, Elisabetta Bernardinello, Nadia Malacarne, Silvana Bortoli, Fabiola Talato, Agostino Corsini, Maria Licursi, Nicoletta Marcon, Angela Sansone), the nurses and other personnel at OIC who were essential to complete the study successfully.

Conflicts of Interest: The other authors declare no conflict of interest.

\section{References}

1. da Silva, P.F.L.; Schumacher, B. DNA damage responses in ageing. Open Biol. 2019, 9, 190168. [CrossRef]

2. Nikitaki, Z.; Hellweg, C.E.; Georgakilas, A.G.; Ravanat, J.-L. Stress-induced DNA damage biomarkers: Applications and limitations. Front. Chem. 2015, 3, 35. [CrossRef] [PubMed] 
3. EFSA NDA Panel (EFSA Panel on Dietetic Products, Nutrition and Allergies); Turck, D.; Bresson, J.-L.; Burlingame, B.; Dean, T.; Fairweather-Tait, S.; Heinonen, M.; Hirsch-Ernst, K.I.; Mangelsdorf, I.; McArdle, H.J.; et al. Guidance for the scientific requirements for health claims related to antioxidants, oxidative damage and cardiovascular health (Revision 1). EFSA J. 2018, $16,5136$.

4. Martini, D.; Rossi, S.; Biasini, B.; Zavaroni, I.; Bedogni, G.; Musci, M.; Pruneti, C.; Passeri, G.; Ventura, M.; Di Nuzzo, S.; et al. Claimed effects, outcome variables and methods of measurement for health claims proposed under European Community Regulation 1924/2006 in the framework of protection against oxidative damage and cardiovascular health. Nutr. Metab. Cardiovasc. Dis. 2017, 27, 473-503. [CrossRef]

5. Valavanidis, A.; Vlachogianni, T.; Fiotakis, C. 8-hydroxy-2'-deoxyguanosine (8-OHdG): A critical biomarker of oxidative stress and carcinogenesis. J. Environ. Sci. Health C Environ. Carcinog. Ecotoxicol. Rev. 2009, 27, 120-139. [CrossRef] [PubMed]

6. Singh, N.P. The comet assay: Reflections on its development, evolution and applications. Mutat. Res. Rev. Mutat. Res. 2016, 767, 23-30. [CrossRef]

7. Møller, P.; Azqueta, A.; Boutet-Robinet, E.; Koppen, G.; Bonassi, S.; Milić, M.; Gajski, G.; Costa, S.; Paulo Teixeira, J.; Pereira, C.C.; et al. Minimum Information for Reporting on the Comet Assay (MIRCA): Recommendations for describing comet assay procedures and results. Nat. Protoc. 2020, 15, 3817-3826. [CrossRef] [PubMed]

8. Pu, X.; Wang, Z.; Klaunig, J.E. Alkaline comet assay for assessing DNA damage in individual cells. Curr. Protoc. Toxicol. 2015, 65, 3.12.1-3.12.11. [CrossRef] [PubMed]

9. Azqueta, A.; Ladeira, C.; Giovannelli, L.; Boutet-Robinet, E.; Bonassi, S.; Neri, M.; Gajski, G.; Duthie, S.; Del Bo', C.; Riso, P.; et al. Application of the comet assay in human biomonitoring: An hCOMET perspective. Mutat. Res. 2020, 783, 108288. [CrossRef] [PubMed]

10. Muruzabal, D.; Collins, A.; Azqueta, A. The enzyme-modified comet assay: Past, present and future. Food Chem. Toxicol. 2021, 147, 111865. [CrossRef]

11. Collins, A.; Vettorazzi, A.; Azqueta, A. The role of the enzyme-modified comet assay in in vivo studies. Toxicol. Lett. 2020, 327, 58-68. [CrossRef] [PubMed]

12. Pinto Soares, P.; Cortinhas, A.; Bento, T.; Carlos Leitão, J.; Collins, A.R.; Gaivã, I.; Mota, M.P. Aging and DNA damage in humans: A meta-analysis study. Aging 2014, 6, 432-439. [CrossRef] [PubMed]

13. Yousefzadeh, M.; Henpita, C.; Vyas, R.; Soto-Palma, C.; Robbins, P.; Niedernhofer, L. DNA damage-How and why we age? eLife 2021, 10, e62852. [CrossRef]

14. Sies, H.; Berndt, C.; Jones, D.P. Oxidative stress. Annu. Rev. Biochem. 2017, 86, 715-748. [CrossRef]

15. Rea, I.M.; Gibson, D.S.; McGilligan, V.; McNerlan, S.E.; Denis Alexander, H.; Ross, O.A. Age and age-related diseases: Role of inflammation triggers and cytokines. Front. Immunol. 2018, 9, 586. [CrossRef]

16. Vetrani, C.; Costabile, G.; Di Marino, L.; Rivellese, A.A. Nutrition and oxidative stress: A systematic review of human studies. Int. J. Food Sci. Nutr. 2013, 64, 312-326. [CrossRef]

17. Böhm, V.; Lietz, G.; Olmedilla-Alonso, B.; Phelan, D.; Reboul, E.; Bánati, D.; Borel, P.; Corte-Real, J.; de Lera, A.R.; Desmarchelier, C.; et al. From carotenoid intake to carotenoid blood and tissue concentrations-Implications for dietary intake recommendations. Nutr. Rev. 2021, 79, 544-573. [CrossRef]

18. Marino, M.; Del Bo', C.; Martini, D.; Porrini, M.; Riso, P. A Review of Registered Clinical Trials on Dietary (Poly)Phenols: Past Efforts and Possible Future Directions. Foods 2020, 9, 1606. [CrossRef]

19. Costanzo, G.; Iesce, M.R.; Naviglio, D.; Ciaravolo, M.; Vitale, E.; Arena, C. Comparative Studies on Different Citrus Cultivars: A Revaluation of Waste Mandarin Components. Antioxidants 2020, 9, 517. [CrossRef]

20. Peritore, A.F.; Siracusa, R.; Crupi, R.; Cuzzocrea, S. Therapeutic Efficacy of Palmitoylethanolamide and Its New Formulations in Synergy with Different Antioxidant Molecules Present in Diets. Nutrients 2019, 11, 2175. [CrossRef]

21. Riso, P.; Martini, D.; Visioli, F.; Martinetti, A.; Porrini, M. Effect of broccoli intake on markers related to oxidative stress and cancer risk in healthy smokers and nonsmokers. Nutr. Cancer 2009, 61, 232-237. [CrossRef]

22. Riso, P.; Martini, D.; Møller, P.; Loft, S.; Bonacina, G.; Moro, M.; Porrini, M. DNA damage and repair activity after broccoli intake in young healthy smokers. Mutagenesis 2010, 25, 595-602. [CrossRef] [PubMed]

23. Del Bo', C.; Martini, D.; Vendrame, S.; Riso, P.; Ciappellano, S.; Klimis-Zacas, D.; Porrini, M. Improvement of lymphocyte resistance against $\mathrm{H}_{2} \mathrm{O}_{2}$-induced DNA damage in Sprague-Dawley rats after eight weeks of a wild blueberry (Vaccinium angustifolium)-enriched diet. Mutat. Res. 2010, 703, 158-162. [CrossRef] [PubMed]

24. Proshkina, E.; Shaposhnikov, M.; Moskalev AInt, J. Genome-protecting compounds as potential geroprotectors. Int. J. Mol. Sci. 2020, 21, 4484. [CrossRef] [PubMed]

25. Kaźmierczak-Barańska, J.; Boguszewska, K.; Karwowski, B.T. Nutrition can help DNA repair in the case of aging. Nutrients 2020, 12, 3364. [CrossRef]

26. Włodarczyk, M.; Nowicka, G. Obesity, DNA damage, and development of obesity-related diseases. Int. J. Mol. Sci. 2019, 20, 1146. [CrossRef]

27. Freitas, A.A.; de Magalhães, J.P. A review and appraisal of the DNA damage theory of ageing. Mutat. Res. 2011, 728, 12-22. [CrossRef] [PubMed]

28. Piperakis, S.M.; Kontogianni, K.; Karanastasi, G.; Iakovidou-Kritsi, Z.; Piperakis, M.M. The use of comet assay in measuring DNA damage and repair efficiency in child, adult, and old age populations. Cell Biol. Toxicol. 2009, 25, 65-71. [CrossRef] 
29. Lian, P.; Braber, S.; Garssen, J.; Wichers, H.J.; Folkerts, G.; Fink-Gremmels, J.; Varasteh, S. Beyond heat stress: Intestinal integrity disruption and mechanism-based intervention strategies. Nutrients 2020, 12, 734. [CrossRef]

30. Guglielmetti, S.; Bernardi, S.; Del Bo', C.; Cherubini, A.; Porrini, M.; Gargari, G.; Hidalgo-liberona, N.; Gonzalez-dominguez, R.; Peron, G.; Zamora-Ros, R.; et al. Effect of a polyphenol-rich dietary pattern on intestinal permeability and gut and blood microbiomics in older subjects: Study protocol of the MaPLE randomised controlled trial. BMC Geriatr. 2020, 20, 77. [CrossRef]

31. Martini, D.; Bernardi, S.; Del Bo', C.; Hidalgo Liberona, N.; Zamora-Ros, R.; Tucci, M.; Cherubini, A.; Porrini, M.; Gargari, G.; González-Domínguez, R.; et al. Estimated Intakes of Nutrients and Polyphenols in Participants Completing the MaPLE Randomised Controlled Trial and Its Relevance for the Future Development of Dietary Guidelines for the Older Subjects. Nutrients 2020, 12, 2458. [CrossRef] [PubMed]

32. Seefeldt, V.D.; Harrison, G.G. Anthropometric Standardization Reference Manual; Lohman, T.G., Roche, A.F., Martorell, R., Eds.; Human Kinetics Books: Champaign, IL, USA, 1988; p. 111.

33. Chobanian, A.V.; Bakris, G.L.; Black, H.R.; Cushman, W.C.; Green, L.A.; Izzo, J.L., Jr.; Jones, D.W.; Materson, B.J.; Oparil, S.; Wright, J.T., Jr.; et al. Joint National Committee on Prevention, Detection, Evaluation, and Treatment of High Blood Pressure. National Heart, Lung, and Blood Institute; National High Blood Pressure Education Program Coordinating Committee Seventh report of the joint National Committee on prevention, detection, evaluation, and treatment of high blood pressure. Hypertension 2003, 42, 1206-1252. [PubMed]

34. Del Bo', C.; Bernardi, S.; Cherubini, A.; Porrini, M.; Zamora-ros, R.; Peron, G.; Marino, M.; Gigliotti, L.; Winterbone, M.S.; Kirkup, B.; et al. A polyphenol-rich dietary pattern improves intestinal permeability, evaluated as serum zonulin levels, in older subjects: The MaPLE randomised controlled trial. Clin. Nutr. 2020. [CrossRef]

35. Del Bo', C.; Fracassetti, D.; Lanti, C.; Porrini, M.; Riso, P. Comparison of DNA damage by the comet assay in fresh versus cryopreserved peripheral blood mononuclear cells obtained following dietary intervention. Mutagenesis 2015, 30, 29-35. [CrossRef] [PubMed]

36. Løhr, M.; Jensen, A.; Eriksen, L.; Grønbæk, M.; Loft, S.; Møller, P. Age and metabolic risk factors associated with oxidatively damaged DNA in human peripheral blood mononuclear cells. Oncotarget 2015, 6, 2641-2653. [CrossRef] [PubMed]

37. Sirota, N.P.; Kuznetsova, E.A. Spontaneous DNA damage in peripheral blood leukocytes from donors of different age. Bull. Exp. Biol. Med. 2008, 145, 194-197. [CrossRef] [PubMed]

38. Humphreys, V.; Martin, R.M.; Ratcliffe, B.; Duthie, S.; Wood, S.; Gunnell, D.; Collins, A.R. Age-related increases in DNA repair and antioxidant protection: A comparison of the Boyd Orr Cohort of elderly subjects with a younger population sample. Age Ageing 2007, 36, 521-526. [CrossRef] [PubMed]

39. Møller, P. Effect of age and sex on the level of DNA strand breaks and oxidatively damaged DNA in human blood cells. Mutat. Res. Genet. Toxicol. Environ. Mutagen. 2019, 838, 16-21. [CrossRef]

40. Del Bo', C.; Marino, M.; Martini, D.; Tucci, M.; Ciappellano, S.; Riso, P.; Porrini, M. Overview of human intervention studies evaluating the impact of the Mediterranean diet on markers of DNA damage. Nutrients 2019, 11, 391. [CrossRef] [PubMed]

41. Kazimírová, A.; Barancoková, M.; Volkovová, K.; Staruchová, M.; Krajcovicová-Kudlácková, M.; Wsólová, L. Does a vegetarian diet influence genomic stability? Eur. J. Nutr. 2004, 43, 32-38. [CrossRef]

42. Bishop, K.S.; Erdrich, S.; Karunasinghe, N.; Han, D.Y.; Zhu, S.; Jesuthasan, A.; Ferguson, L.R. An investigation into the association between DNA damage and dietary fatty acid in men with prostate cancer. Nutrients 2015, 7, 405-422. [CrossRef] [PubMed]

43. Tan, B.L.; Norhaizan, M.E.; Liew, W.P. Nutrients and oxidative stress: Friend or foe? Oxid. Med. Cell Longev. 2018, $2018,9719584$. [CrossRef]

44. Barber, T.M.; Kabisch, S.; Pfeiffer, A.F.H.; Weickert, M.O. The health benefits of dietary fibre. Nutrients 2020, 12, 3209. [CrossRef] [PubMed]

45. Włodarczyk, M.; Jabłonowska-Lietz, B.; Olejarz, W.; Nowicka, G. Anthropometric and dietary factors as predictors of DNA damage in obese women. Nutrients 2018, 10, 578. [CrossRef] [PubMed]

46. Duthie, S.J.; Narayanan, S.; Brand, G.M.; Pirie, L.; Grant, G. Impact of folate deficiency on DNA stability. J. Nutr. 2002,132 (Suppl. 8), 2444S-2449S. [CrossRef]

47. Ames, B.N. DNA damage from micronutrient deficiencies is likely to be a major cause of cancer. Mutat. Res. 2001, 475, 7-20. [CrossRef]

48. Kuwahara, K.; Nanri, A.; Pham, N.M.; Kurotani, K.; Kume, A.; Sato, M.; Kawai, K.; Kasai, H.; Mizoue, T. Serum vitamin B6, folate, and homocysteine concentrations and oxidative DNA damage in Japanese men and women. Nutrition 2013, 29, 1219-1223. [CrossRef] [PubMed]

49. Ferguson, L.R.; Fenech, M.F. Vitamin and minerals that influence genome integrity, and exposure/intake levels associated with DNA damage prevention. Mutat. Res. 2012, 733, 1-3. [CrossRef] [PubMed]

50. Fenech, M. Recommended dietary allowances (RDAs) for genomic stability. Mutat. Res. 2001, 480-481, 51-54. [CrossRef]

51. Ladeira, C.; Carolino, E.; Gomes, M.C.; Brito, M. Role of macronutrients and micronutrients in DNA damage: Results from a Food Frequency Questionnaire. Nutr. Metab. Insights 2017, 10, 117863881668466. [CrossRef] [PubMed]

52. Smith, D.F.; MacGregor, J.T.; Hiatt, R.A.; Hooper, N.K.; Wehr, C.M.; Peters, B.; Goldman, L.R.; Yuan, L.A.; Smith, P.A.; Becker, C.E. Micronucleated erythrocytes as an index of cytogenetic damage in humans: Demographic and dietary factors associated with micronucleated erythrocytes in splenectomized subjects. Cancer Res. 1990, 50, 5049-5054. 
53. Dhalaria, R.; Verma, R.; Kumar, D.; Puri, S.; Tapwal, A.; Kumar, V.; Nepovimova, E.; Kuca, K. Bioactive compounds of edible fruits with their anti-aging properties: A comprehensive review to prolong human life. Antioxidants 2020, 9, 1123. [CrossRef]

54. Tan, B.L.; Norhaizan, M.E.; Liew, W.P.; Sulaiman Rahman, H. Antioxidant and oxidative stress: A mutual interplay in age-related diseases. Front. Pharmacol. 2018, 9, 1162. [CrossRef] [PubMed]

55. Azqueta, A.; Collins, A. Polyphenols and DNA damage: A mixed blessing. Nutrients 2016, 8, 785. [CrossRef]

56. Del Bo' , C.; Porrini, M.; Campolo, J.; Parolini, M.; Lanti, C.; Klimis-Zacas, D.; Riso, P. A single blueberry (Vaccinium corymbosum) portion does not affect markers of antioxidant defence and oxidative stress in healthy volunteers following cigarette smoking. Mutagenesis 2016, 31, 215-224. [CrossRef] [PubMed]

57. Del Bo', C.; Bernardi, S.; Marino, M.; Porrini, M.; Tucci, M.; Guglielmetti, S.; Cherubini, A.; Carrieri, B.; Kirkup, B.; Kroon, P.; et al. Systematic review on polyphenol intake and health outcomes: Is there sufficient evidence to define a health-promoting polyphenol-rich dietary pattern? Nutrients 2019, 11, 1355.

58. Del Bo', C.; Riso, P.; Campolo, J.; Møller, P.; Loft, S.; Klimis-Zacas, D.; Brambilla, A.; Rizzolo, A.; Porrini, M. A single portion of blueberry (Vaccinium corymbosum L.) improves protection against DNA damage but not vascular function in healthy male volunteers. Nutr. Res. 2013, 33, 220-227. [CrossRef]

59. Riso, P.; Klimis-Zacas, D.; Del Bo', C.; Martini, D.; Campolo, J.; Vendrame, S.; Møller, P.; Loft, S.; De Maria, R.; Porrini, M. Effect of a wild blueberry (Vaccinium angustifolium) drink intervention on markers of oxidative stress, inflammation and endothelial function in humans with cardiovascular risk factors. Eur. J. Nutr. 2013, 52, 949-961. [CrossRef] [PubMed]

60. Martini, D.; Del Bo', C.; Tassotti, M.; Riso, P.; Del Rio, D.; Brighenti, F.; Porrini, M. Coffee consumption and oxidative stress: A review of human intervention studies. Molecules 2016, 21, 979. [CrossRef] [PubMed]

61. Rabassa, M.; Zamora-Ros, R.; Andres-Lacueva, C.; Urpi-Sarda, M.; Bandinelli, S.; Ferrucci, L.; Cherubini, A. Association between both total baseline urinary and dietary polyphenols and substantial physical performance decline risk in older adults: A 9-year follow-up of the InCHIANTI study. J. Nutr. Health Aging 2016, 20, 478-484. [CrossRef]

62. Setayesh, T.; Nersesyan, A.; Mišík, M.; Ferk, F.; Langie, S.; Andrade, V.M.; Haslberger, A.; Knasmüller, S. Impact of obesity and overweight on DNA stability: Few facts and many hypotheses. Mutat. Res. 2018, 777, 64-91. [CrossRef] [PubMed]

63. Tomasello, B.; Malfa, G.; Galvano, F.; Reins, M. DNA damage in normal-weight obese syndrome measured by Comet assay. Mediterr. J. Nutr. Metab. 2011, 2, 99-104. [CrossRef]

64. Adenan, D.M.; Jaafar, Z.; Jayapalan, J.J.; Abdul Aziz, A. Plasma antioxidants and oxidative stress status in obese women: Correlation with cardiopulmonary response. PeerJ 2020, 8, e9230. [CrossRef]

65. Awad, M.A.; Aldosari, S.R.; Abid, M.R. Genetic alterations in oxidant and antioxidant enzymes in the vascular system. Front. Cardiovasc. Med. 2018, 5, 107. [CrossRef]

66. Wei, Y.P.; Jia, C.N.; Lan, Y.; Hou, X.Q.; Zuo, J.J.; Cui, H.; Guan, X.J.; Wang, Y.; Mao, G.Y. Serum cholesterol positively associated with oxidative DNA damage: A propensity score-matched analysis. Free Radic. Res. 2019, 53, 411-417. [CrossRef] [PubMed]

67. De Barros, K.V.; De Abreu, C.G.; Xavier, R.A.; Ribeiro, M.L.; Gambero, A.; de Oliveira Carvalho, P.; Silveira, V.L. Effects of a high fat or a balanced omega 3/omega 6 diet on cytokines levels and DNA damage in experimental colitis. Nutrition 2011, 27, 221-226. [CrossRef] [PubMed]

68. Anderson, R.F.; Harris, T.A. Dopamine and uric acid act as antioxidants in the repair of DNA radicals: Implications in Parkinson's disease. Free Radic. Res. 2003, 37, 1131-1136. [CrossRef]

69. Foksinski, M.; Gackowski, D.; Rozalski, R.; Siomek, A.; Guz, J.; Szpila, A.; Dziaman, T.; Olinski, R. Effects of basal level of antioxidants on oxidative DNA damage in humans. Eur. J. Nutr. 2007, 46, 174-180. [CrossRef] [PubMed]

70. Ruggiero, C.; Cherubini, A.; Ble, A.; Bos, A.J.; Maggio, M.; Dixit, V.D.; Lauretani, F.; Bandinelli, S.; Senin, U.; Ferrucci, L. Uric acid and inflammatory markers. Eur. Heart J. 2006, 27, 1174-1181. [CrossRef] [PubMed]

71. Gormally, B.M.G.; Fuller, R.; McVey, M.; Romero, L.M. DNA damage as an indicator of chronic stress: Correlations with corticosterone and uric acid. Comp. Biochem. Physiol. A Mol. Integr. Physiol. 2019, 227, 116-122. [CrossRef]

72. Ndrepepa, G. Uric acid and cardiovascular disease. Clin. Chim. Acta 2018, 484, 150-163. [CrossRef] [PubMed]

73. Brombo, G.; Bonetti, F.; Volpato, S.; Morieri, M.L.; Napoli, E.; Bandinelli, S.; Cherubini, A.; Maggio, M.; Guralnik, J.; Ferrucci, L.; et al. Uric acid within the "normal" range predict 9-year cardiovascular mortality in older individuals. The InCHIANTI study. Nutr. Metab. Cardiovasc. Dis. 2019, 29, 1061-1067. [CrossRef]

74. Bernardi, S.; Del Bo', C.; Marino, M.; Gargari, G.; Cherubini, A.; Andrés-Lacueva, C.; Hidalgo-Liberona, N.; Peron, G.; GonzálezDominguez, R.; Kroon, P.; et al. Polyphenols and Intestinal Permeability: Rationale and Future Perspectives. J. Agric. Food Chem. 2020, 68, 1816-1829. [CrossRef]

75. Söderholm, J.D.; Perdue, M.H. Stress and gastrointestinal tract. II. Stress and intestinal barrier function. Am. J. Physiol. Gastrointest. Liver Physiol. 2001, 280, G7-G13. [CrossRef] [PubMed] 